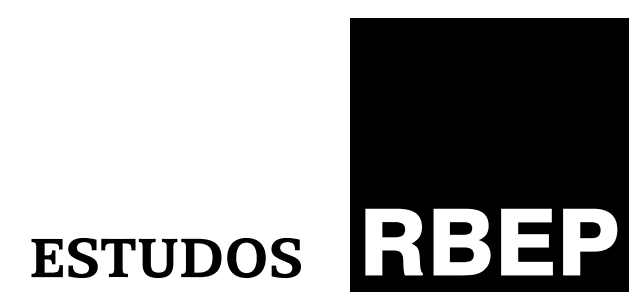

\title{
Contribuições para o aprimoramento da Provinha Brasil enquanto instrumento diagnóstico do nível de alfabetização e letramento nas séries iniciais
}

Raquel Meister Ko Freitag

Ayane Nazarela Santos Almeida

Mônica Maria Soares Rosário

\section{Resumo}

A Provinha Brasil é uma avaliação diagnóstica do nível de habilidades de alfabetização e letramento que, assim como outros instrumentos avaliativos, apresenta limitações e incompletudes que podem prejudicar a abrangência dos resultados encontrados. No intuito de colaborar para o aprimoramento desse instrumento, apresentamos a análise de três aspectos relacionados à concepção e elaboração da Provinha Brasil: a avaliação da competência narrativa dos alfabetizandos, o tratamento da variação linguística e a formação do professor alfabetizador.

Palavras-chave: Provinha Brasil; competência narrativa; competência sociolinguística; formação docente. 


\section{Abstract \\ Contributions to Provinha Brasil's improvment as a tool for diagnosis of reading in initial series}

Provinha Brasil is a Brazilian diagnostic assessment of literacy skills that is as limited and incomplete as any other evaluation instrument. This fact can make the results less effective. Thus, in order to contribute to the improvement of the test, we present an analysis of three aspects related to the design and development of Provinha Brazil: the evaluation of narrative competence, the treatment of linguistic variation and the formation of literacy teachers.

Keywords: Provinha Brasil; narrative competence; sociolinguistic competence; teachers formation.

\section{Introdução}

Em 2007, o governo federal, por meio do Decreto $n^{\circ}$ 6.094, lançou o Plano de Metas Compromisso Todos pela Educação, que consiste na "conjugação dos esforços da União, Estados, Distrito Federal e Municípios, atuando em regime de colaboração, das famílias e da comunidade, em proveito da melhoria da qualidade da educação básica" (Brasil. Decreto..., 2007, p. 1). O plano instituiu uma série de medidas, como a alfabetização até os 8 anos de idade, para reverter o quadro do fracasso escolar, atribuindo à educação a devida importância social, política e econômica para o desenvolvimento do País. Em adesão a esse compromisso, o Instituto Nacional de Estudos e Pesquisas Educacionais Anísio Teixeira (Inep) criou uma avaliação a fim de diagnosticar o nível de alfabetização das crianças matriculadas no $2^{\circ}$ ano de escolarização das escolas públicas brasileiras - a Provinha Brasil. No escopo do projeto Ler + Sergipe: leitura para o letramento e cidadania (Observatório da Educação 2010), buscamos identificar a concepção de leitura subjacente aos documentos oficiais, aos indicadores de desempenho e às matrizes de competência, com o intuito de verificar as convergências e divergências e como estas estão relacionadas e influenciam a habilidade de leitura do estudante. Elegemos como objeto de análise o instrumento Provinha Brasil.

De acordo com o Ministério da Educação (MEC), a Avaliação de Alfabetização Provinha Brasil difere dos demais mecanismos avaliativos realizados pelo Inep por conferir autonomia a professores e/ou gestores na sua aplicação e na utilização dos seus resultados, uma vez que fornece respostas diretamente aos alfabetizadores e gestores da escola, por possuir uma metodologia de aplicação que possibilita uma imediata leitura e interpretação dos resultados, reforçando, portanto, o seu caráter diagnóstico e não classificatório (Brasil. Inep, 2011c). Tal avaliação 
não integra a composição do Índice de Desenvolvimento da Educação Básica (Ideb), mas consiste em um subsídio de orientação para gerar ações políticas e pedagógicas que, juntamente com outras iniciativas de aperfeiçoamento e redirecionamento das práticas educativas, podem promover uma alavancagem dos índices apresentados com níveis mais satisfatórios de alfabetização e letramento.

A primeira realização da Provinha Brasil deu-se em abril de 2008 e, desde então, busca-se o aperfeiçoamento de suas potencialidades tanto para avaliar a aprendizagem quanto para monitorar o processo de alfabetização de crianças do $2^{\circ}$ ano de escolarização das escolas públicas brasileiras. A primeira edição dessa avaliação conteve três questões envolvendo a escrita de palavras e frases, além de 24 questões de múltipla escolha, com quatro opções cada uma. A partir de 2009, os itens de escrita não foram incluídos no teste em função de limitações técnicas para a correção; desde então, a Provinha Brasil passou a conter apenas 24 questões de múltipla escolha, que, em 2011, foram reduzidas para 20. Essa redução do número de questões do teste representou uma mudança no sentido de atribuir maior objetividade ao instrumental da avaliação.

Realizada em duas etapas distintas - no início do $2^{\circ}$ ano de escolarização e no término do mesmo ano letivo -, a avaliação possibilita uma análise mais precisa sobre o que foi efetivamente realizado na aprendizagem das crianças. Os dois resultados são comparados, possibilitando o diagnóstico da evolução no processo de aprimoramento de competências e habilidades e de possíveis deficiências no desenvolvimento das habilidades de leitura e escrita. Desse modo, os professores podem identificar as dificuldades na aprendizagem dos alunos e redimensionar sua prática, planejando novas ações e priorizando os assuntos aos quais devem dedicar maior atenção durante as aulas. A Provinha Brasil subsidia o desenvolvimento de mecanismos com os quais os professores poderão, com autonomia, redefinir o plano de ensino e aprendizagem.

Apesar de a Provinha Brasil intencionar contribuir para a formulação de políticas que promovam o avanço do ensino de alfabetização, ainda se trata de um instrumento diagnóstico que precisa ser lapidado. Alguns autores concentram-se em apontar suas incoerências, desde os seus pressupostos até a análise dos resultados e suas propostas de trabalho. Esteban (2009) entende que a Provinha Brasil é uma avaliação nacional rígida, redutora e que, por isso, compromete qualquer vertente sociocultural que a constitui. Esteban (2009) afirma que na concepção da Provinha Brasil impera desconhecimento do universo da aprendizagem e do processo de alfabetização ao estabelecer uma relação entre aplicação da avaliação e garantia da alfabetização infantil em um período máximo de 8 anos de idade. A autora ressalta o caráter classificatório da Provinha Brasil ao mencionar a inserção dos alunos em uma escala rígida, previamente determinada, em que a aprendizagem é mensurada por meio de técnicas de controle. Esteban (2009) também denuncia uma suposta desqualificação 
da ação docente e da capacidade do professor de administrar sua prática diária, já que não é confiada a ele a incumbência de elaborar ou interpretar os resultados da avaliação, mas simplesmente de aplicar e corrigir. Dando seguimento às desqualificações, as crianças também, considerando a proposta diminutiva de provinha, são estereotipadas como alguém que se prepara para ser, mas ainda não é.

Ao afirmar que a proposta apresenta um caráter reducionista, Esteban (2009) destaca que a Provinha Brasil implanta um abismo entre a realidade vivida pelos sujeitos e os resultados alcançados. Independentemente da classe social e do meio em que vivem, as crianças são submetidas, a partir dos resultados, às mesmas propostas de trabalho, podendo ser totalmente desarticuladas, distanciadas do cotidiano escolar e do contexto sociocultural.

De forma menos acirrada, Cristofolini $(2010,2012)$ questiona o foco exclusivo dado à alfabetização, já que a Provinha Brasil se propõe a analisar também o letramento. Em seu estudo da edição de 2009 da Provinha Brasil, a autora identifica que o instrumento foca principalmente as dimensões linguística e cognitiva da leitura, em detrimento da dimensão sociocultural. A autora afirma que, sendo um instrumento avaliativo padronizado, com uma matriz de referência nacional, não contempla a diversidade sociocultural do Brasil.

A amplitude de uma sala de aula está justamente no diálogo que se estabelece entre as diferenças, ampliando as práticas, expandindo e criando novos conhecimentos. Um processo avaliativo pleno deveria contemplar esta diversidade que constitui de forma privilegiada o espaço escolar, abrindo caminhos para o aproveitamento de novas possibilidades de crescimento, aprendizagem e incorporação das divergências.

Ratificando a importância da Provinha Brasil, Morais, Leal e Albuquerque consideram a necessidade de uma análise cuidadosa sobre o que está sendo feito na sala de aula de alfabetização visando a um ensino eficiente que garanta aos alunos o direito de aprender, ao afirmarem que

[...] a criação do Provinha Brasil pode representar uma política importantíssima para a qualificação do ensino oferecido às crianças brasileiras [...] o diagnóstico precoce das aprendizagens dos pequenos alfabetizandos não só cumpre uma inadiável necessidade de monitoramento das práticas de alfabetização em nossas redes públicas de ensino, como deve colaborar para a definição de políticas de formação continuada e de práticas de ensino inclusivas no interior da escola, através do atendimento eficaz às diversidades de ritmos e estilos dos alunos. (Morais; Leal; Albuquerque, 2009, p. 302).

Os autores apresentam como qualidade da Provinha Brasil ser este um instrumento de diagnóstico precoce, em que é possível detectar tanto as aprendizagens efetivamente realizadas quanto as dificuldades manifestadas nesse processo, possibilitando a intervenção por parte de professores e gestores com o objetivo de saná-las. Além disso, pode servir 
de subsídio para a definição de políticas não só de formação de professores, mas também de seleção de recursos didáticos que busquem atender às necessidades dos aprendizes. Outra virtude destacada pelos autores é a de possibilitar a verificação de como as crianças se apropriam do sistema alfabético ao traçar, de forma específica, os itens contemplados pelos seus instrumentos, enfocando habilidades relacionadas aos princípios da base alfabética, bem como a de delimitar o período escolar em que devem ser consolidadas tais habilidades.

Apesar de concordarmos com a necessidade de revisão dos pressupostos norteadores do instrumento, não pretendemos negar a sua importância enquanto exame diagnóstico de algumas habilidades de alfabetização e letramento. Afinal, assim como outros instrumentos avaliativos, a Provinha Brasil apresenta limitações e incompletudes que podem prejudicar a abrangência dos resultados encontrados, mas também, por meio desses resultados, é possível empenhar esforços no intuito de favorecer o desenvolvimento da criança desde o domínio das propriedades do sistema alfabético até tornar-se um leitor minimamente proficiente, identificando as correspondências gráficas da língua portuguesa. Além disso, tais limitações podem ser sanadas com base nas experiências adquiridas ao longo das aplicações dessa avaliação. É essa linha de argumentação que iremos focar neste texto, apresentando três aspectos relacionados à concepção e elaboração da Provinha Brasil: a avaliação da competência narrativa dos alfabetizandos, o tratamento da variação linguística e a formação do professor alfabetizador.

\section{A competência narrativa dos alfabetizandos e o seu desempenho na Provinha Brasil ${ }^{1}$}

Entende-se por narrativa todo discurso que apresenta uma história que, embora imaginária, possui características de realidade e é formada por uma ou várias personagens em tempo e espaço definidos. Devido ao fato de ser encontrada nas mais diversas culturas, possuir uma diversidade de funções e formas e estar sempre associada à experiência humana, despertando ideias, sentimentos e aguçando sensações, é o gênero tido como o mais universal.

Inumeráveis são as narrativas do mundo. É de início uma variedade prodigiosa de gêneros, eles próprios distribuídos entre substâncias diferentes, como se toda matéria fosse boa para o homem confiar-lhe sua narrativa: a narrativa pode ter como suporte a linguagem articulada, oral ou escrita, a imagem, fixa ou móvel, o gesto ou a mistura ordenada de todas essas substâncias; está presente no mito, na lenda, na fábula, no conto, na novela, na epopéia, na história, na tragédia, no drama, na comédia, na pantomima, no quadro pintado (pense-se na Santa Úrsula de Carpaccio), nos vitrais, no cinema, nas histórias em quadrinhos, nas notícias de jornais, na conversa. Além disso, sob essas formas quase infinitas, a narrativa está presente em todos os tempos, em todos os

\footnotetext{
${ }^{1}$ Sumarização dos resultados obtidos no desenvolvimento do subprojeto de pesquisa do Ler+Sergipe: leitura e letramento para a cidadania, que culminou com a dissertação de mestrado intitulada "A competência narrativa na Provinha Brasil: um estudo do desempenho dos estudantes da EMEF Tenisson Ribeiro, Aracaju/ SE" (Almeida, 2012).
} 
lugares, em todas as sociedades (...) internacional, trans-histórica, transcultural, a narrativa está sempre presente, como a vida. (Barthes, 2001, p. 103-104).

Assim, a narrativa não se realiza apenas na estética dos textos literários, mas através de situações funcionais variadas e contextos comunicativos verbais, visuais ou mistos, sendo geralmente classificada num quadro diversificado de ocorrências. As narrativas são gêneros interessantes à prática escolar por permitirem o direcionamento adequado da fala ou da escrita com vista às variadas situações de comunicação. Porém, apesar de sua importância para o desenvolvimento da competência comunicativa, de habilidades físicas, psicossociais e cognitivas, além de permitir analisar e avaliar os principais estágios do processo de aquisição da linguagem atestada por estudos acadêmicos, os documentos norteadores das práticas educativas no Brasil não apresentam protocolos de avaliação padronizados, que possibilitem ao professor acompanhar o desenvolvimento linguístico de seus alunos. Não encontramos instrumentos de avaliação que auxiliem o professor a explorar os benefícios do trabalho com narrativas em sala de aula, ratificando sua validade teórica e sua utilidade prática e pedagógica. ${ }^{2}$ O aprimoramento da competência narrativa está associado ao processo de letramento que, diferentemente da alfabetização, não consiste apenas na aprendizagem do código alfabético, mas sim no seu uso, considerando o contexto sociocultural em que o indivíduo está inserido. Compete à escola associar o processo de alfabetização ao de letramento, dispondo de gêneros textuais que são parte integrante do cotidiano do aluno, conduzindo-o à aprendizagem da leitura e da escrita enquanto instrumentos de ação social.

Explorar os gêneros textuais na prática docente diária implica em uma atividade educacional que viabiliza o aprendizado, acessando recursos através dos quais o educando pode obter um bom desempenho na produção de narrativas orais e escritas.

As narrativas são utilizadas como uma forma de analisar o comportamento linguístico das crianças, pois, ao contar e ouvir histórias, elas estabelecem uma relação direta com o desenvolvimento da linguagem. Neste contexto, buscamos investigar qual a correlação existente entre o desempenho dos estudantes na Provinha Brasil e o seu desempenho em narrativas. Para isso, elaboramos um protocolo de avaliação de produções narrativas orais e escritas de alfabetizandos, a partir das propostas de Labov e Waletzky (1967) e de Heilmann et al. (2010). Para Heilmann et al. (2010), as narrativas constituem uma rica fonte de dados por consistirem em documentos produzidos pelas crianças a partir de uma linguagem espontânea. As narrativas são um importante componente do currículo escolar, pois as crianças entendem e as usam de forma apropriada e eficaz e a sua documentação permite a avaliação de qualquer tipo de dificuldade de linguagem. De acordo com Heilmann et al. (2010), a competência narrativa pode ser proficiente, emergente ou imatura. 


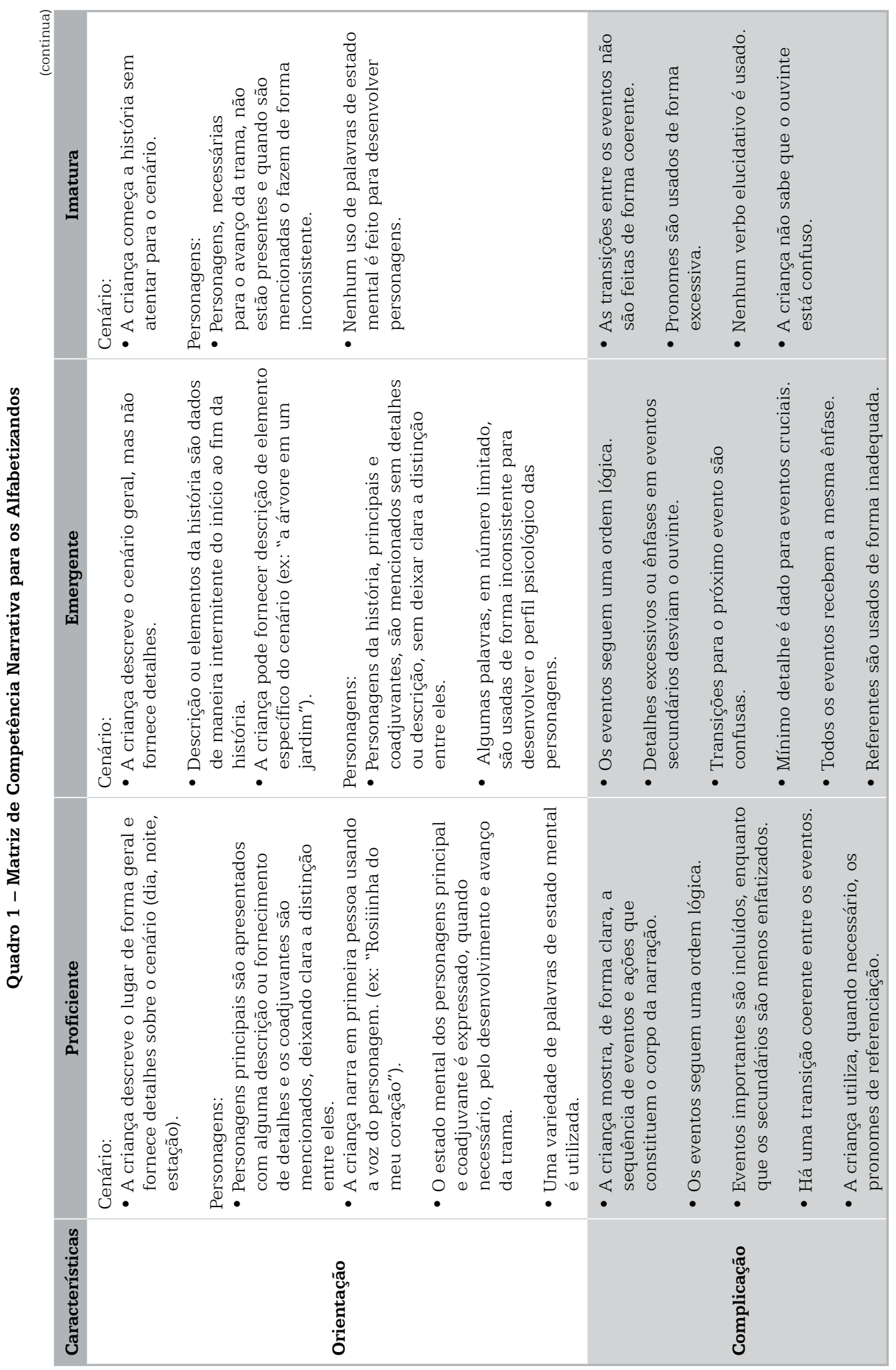




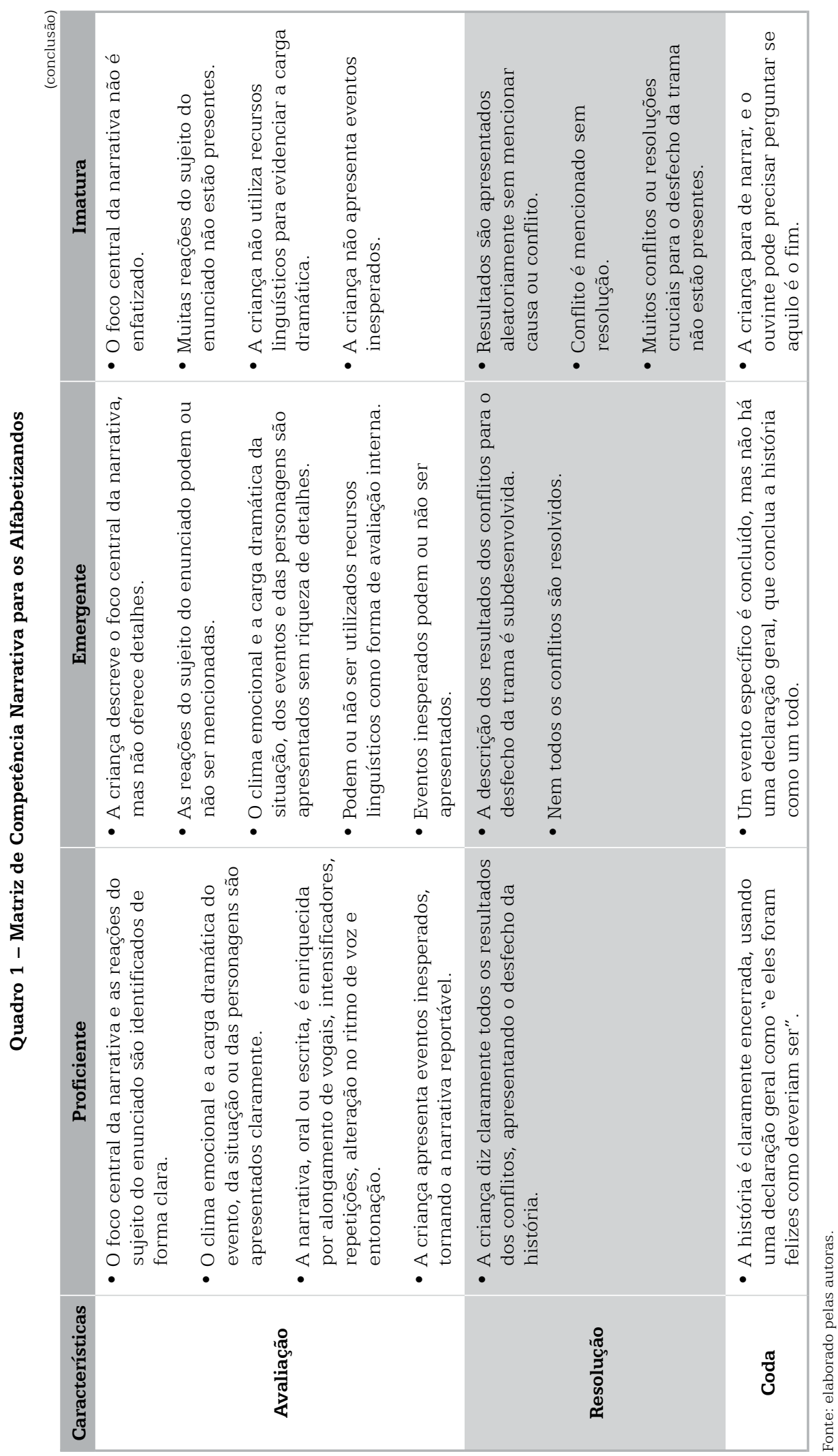


Correlacionamos, por afinidade de competências, os níveis de desempenho na Provinha Brasil 2011 com a competência narrativa. Os níveis de desempenho ou níveis de alfabetização são determinados com base no número de acertos das questões da Provinha Brasil, uma vez que cada uma delas é elaborada visando identificar habilidades previstas nos descritores de competências dos alfabetizandos em relação à leitura. Tais níveis são obtidos através da identificação das habilidades e do grau de dificuldade das questões, levando em consideração um conjunto de acertos e não apenas questões isoladas, tendo, assim, uma referência mais controlada do desempenho do aluno. Desse modo, o barema que determina os níveis de desempenho pode variar de um teste para outro, dependendo da dificuldade do exame.

De acordo com o guia de correção e interpretação de resultados da Provinha Brasil, os alunos do nível 1 sabem:

- Identificar o valor sonoro das partes iniciais e/ou finais de palavras (algumas letras ou sílabas), para "adivinhar" e "ler" o restante da palavra.

- Reconhecer algumas letras do alfabeto e iniciar a distinção das letras de desenhos e outros sinais gráficos. (Brasil. Inep, 2011e, p. 15)

Habilidades do nível 2:

- Estabelecer relação entre letras (grafemas) e sons (fonemas).

- Ler palavras compostas por sílabas formadas por consoante e vogal (sílabas canônicas).

- Ler algumas palavras compostas por sílabas formadas por consoante/vogal/consoante ou por consoante/consoante/vogal (sílabas não canônicas).

- Identificar palavras como unidades gráficas num texto. (Brasil. Inep, 2011e, p. 16).

Habilidades do nível 3:

- Identificar uma mesma palavra escrita com vários tipos de letras.

- Ler palavras compostas por sílabas canônicas e não canônicas.

- Localizar informações, por meio da leitura silenciosa, em uma frase ou em textos de aproximadamente cinco linhas.

- Identificar finalidade de gêneros (convite, anúncio publicitário), apoiando-se em suas características gráficas, como imagens, e em seu modo de apresentação. (Brasil. Inep, 2011e, p. 17).

Habilidades do nível 4:

- Localizar informação em frases de padrão sintático simples e em período composto em ordem direta.

- Identificar o gênero (anedotas, bilhete).

- Identificar finalidade de textos de gêneros diversos, como bilhetes, sumário, convite, cartazes. 
- Antecipar o assunto de um texto a partir de título, subtítulo e imagem.

- Identificar elementos que compõem a narrativa, como tempo, espaço e personagem. (Brasil. Inep, 2011e, p. 18).

As habilidades do nível 5 de desempenho correspondem ao alcance das habilidades desejáveis para os alfabetizandos do $2^{\circ}$ ano de escolarização.

Por se referir a um estágio muito inicial de aprendizagem da língua escrita e domínio das regras que orientam o uso do sistema alfabético para ler e escrever, associamos o nível 1 de desempenho à competência narrativa imatura, em que a criança apresenta dificuldade elevada na produção das narrativas.

Os níveis 2 e 3 de desempenho equivalem à competência narrativa emergente, em que a criança desenvolve a narrativa com algumas das características constituintes, porém com algumas inconsistências. Nesse caso, os alfabetizandos já têm desenvolvidas habilidades relacionadas ao uso do sistema de escrita e têm consolidada a capacidade de ler palavras, frases e textos de curta extensão, além de identificarem a finalidade de gêneros.

A competência narrativa proficiente, constituída por todas as características e elementos que a envolvem, relaciona-se com os níveis de desempenho 4, em que os alunos leem e interpretam textos simples, realizam inferências, reconhecem a finalidade e desenvolvem uma leitura autônoma; e, no nível de desempenho 5, a criança é considerada alfabetizada.

Considerando que os níveis de desempenho propostos com a avaliação da Provinha Brasil não refletem todas as habilidades relativas aos processos de alfabetização e letramento (Brasil. Inep, 2011b), destaca-se a importância desta pesquisa, que, ao desenvolver uma matriz de competência narrativa, permite conjugar suas habilidades com as contempladas na matriz de referência da Provinha Brasil.

O caráter limitado das habilidades contempladas pela matriz de referência da Provinha Brasil, que se restringe ao modelo autônomo de letramento medido através de questões de múltipla escolha, não abrange o todo complexo de habilidades que compõem a caracterização de gêneros textuais como as narrativas, por exemplo, que são enfocadas nesta pesquisa. Tal limitação tem por objetivo tornar possível a mensuração dos resultados conforme suas aplicações. Portanto, é desejável a realização de diagnósticos paralelos mais detalhados e focando uma habilidade específica, como o que propomos.

A coleta de narrativas deu-se em duas etapas, concomitantes à aplicação da Provinha Brasil de 2011, com amostras orais e escritas dos estudantes analisadas de acordo com a matriz de orais e escritas apresentada no Quadro 1. Após a análise das narrativas, o desempenho de cada estudante nas duas aplicações da Provinha Brasil foi cotejado a fim de averiguarmos o quanto este instrumento diagnóstico capta da 
competência narrativa do alfabetizando. A amostra utilizada refere-se aos estudantes que participaram de todas as fases de coleta da pesquisa: Teste 1 da Provinha Brasil, Narrativas orais e escritas 1, Narrativas orais e escritas 2 e Teste 2 da Provinha Brasil, no ano de 2011, em uma turma de $2^{\circ}$ ano do ensino fundamental da Escola Municipal de Ensino Fundamental Tenisson Ribeiro, pertencente à rede pública municipal de Aracaju, no Estado de Sergipe. ${ }^{3}$

Foram coletadas narrativas orais e escritas a partir de uma história em quadrinhos não verbal, enfocando a questão ambiental, da personagem Chico Bento, de Maurício de Sousa (2011). Participaram desta coleta 30 alunos do $2^{\circ}$ ano com faixa etária de 7 a 8 anos, dos quais 12 estiveram presentes em todas as fases da pesquisa. Foram obtidos 12 textos escritos e 7 orais, uma vez que 5 crianças não estavam predispostas a contar as histórias por motivos pessoais, tais como problemas familiares e timidez.

Para alcançarmos o nível de narrativa a partir da média aritmética dos pesos atribuídos a cada elemento estrutural da matriz de competência narrativa proposta neste estudo, definimos escalas equivalentes aos pesos de cada característica narrativa para auferir a competência narrativa a partir da média. Consideramos então que, quando a média resultante dos pesos de cada característica predominante resultou em um valor entre 4 e 5, a competência narrativa foi considerada proficiente, com peso 5; a competência narrativa foi emergente, com peso 3, quando o resultado da média aritmética variou entre 2 e 4; e a competência narrativa foi considerada imatura, com peso 1, quando a média variou em uma escala de 1 a 2, conforme Quadro 2.

\section{Quadro 2 - Escala de Valores para Auferir as Competências Narrativas}

\begin{tabular}{|l|c|c|}
\hline \multicolumn{1}{|c|}{ Competência narrativa } & Peso & Escala \\
\hline Imatura & 1 & $1-2$ \\
\hline Emergente & 3 & $2-4$ \\
\hline Proficiente & 5 & $4-5$ \\
\hline
\end{tabular}

Fonte: elaborado pelas autoras.

Analisando as produções escritas dos alunos nas narrativas orais e escritas 1 e 2, definimos, no Quadro 3, as características de proficiente (P), emergente (E) e imatura (I) a cada uma das macroproposições que as compõem, identificando as habilidades da matriz proposta nas produções dos alunos em análise, que são identificados pelo seu número no diário de classe.

Os resultados das competências narrativas das produções coletadas são calculados a partir da média aritmética dos pesos atribuídos a cada macroproposição, de acordo com as características de proficiente (P), emergente (E) e imatura (I) apresentadas pelos alunos em suas narrativas e que compõem a matriz de competência narrativa proposta (Quadro 1).
${ }^{3} \mathrm{O}$ Ideb da escola pesquisada em 2009 era de 3,7 (meta: 4,0); em 2011, o Ideb foi de 3,1 (meta $4,4)$, caindo $16 \%$ em relação ao anterior e ficando $30 \%$ abaixo da meta estabelecida. 
Analisamos, longitudinalmente, o nível de alfabetização dos alunos nos Testes 1 e 2 da Provinha Brasil e sua relação com o seu desempenho nas produções elaboradas nas narrativas orais e escritas coletadas em concomitância. O Quadro 3 apresenta o comparativo geral, as congruências e incongruências.

Quadro 3 - Comparativo Geral dos Eventos

\begin{tabular}{|c|c|c|c|c|}
\hline Alunos & $\begin{array}{c}\text { Teste 1 } \\
\text { Provinha } \\
\text { Brasil }\end{array}$ & $\begin{array}{c}\text { Narrativas orais } \\
\text { e escritas } 1\end{array}$ & $\begin{array}{c}\text { Narrativas orais } \\
\text { e escritas 2 }\end{array}$ & $\begin{array}{c}\text { Teste 2 } \\
\text { Provinha } \\
\text { Brasil }\end{array}$ \\
\hline 1 & 3 & $\mathrm{I}=1,8$ & $\mathrm{E}=3,4$ & 4 \\
\hline 2 & 3 & $\mathrm{I}=1,0$ & $\mathrm{E}=3,8$ & 3 \\
\hline 4 & 2 & $\mathrm{I}=1,0$ & $\mathrm{I}=1,0$ & 3 \\
\hline 8 & 3 & $\mathrm{I}=1,4$ & $\mathrm{P}=4,2$ & 3 \\
\hline 12 & 3 & $\mathrm{I}=1,0$ & $\mathrm{P}=4,6$ & 3 \\
\hline 14 & 5 & $\mathrm{P}=5,0$ & $\mathrm{P}=5,0$ & 4 \\
\hline 17 & 3 & $\mathrm{I}=1,8$ & $\mathrm{E}=3,8$ & 3 \\
\hline 18 & 3 & $\mathrm{I}=1,0$ & $\mathrm{I}=1,0$ & 4 \\
\hline 20 & 4 & $\mathrm{I}=1,0$ & $\mathrm{E}=3,8$ & 3 \\
\hline 30 & 3 & $\mathrm{I}=1,0$ & $\mathrm{E}=2,2$ & 3 \\
\hline
\end{tabular}

Fonte: Dados da pesquisa

Observamos que os estudantes em acompanhamento longitudinal, com exceção do 14, nas suas primeiras produções, mostraram uma competência narrativa imatura, o que equivaleria ao nível 1 de alfabetização, no entanto, obtiveram níveis 2, 3 e até 4 no Teste 1 da Provinha Brasil. Nas Narrativas orais e escritas 2, dez alunos evoluíram na sua competência narrativa, seis deles passaram a apresentar características predominantemente emergentes em suas narrativas e quatro passaram de imatura à proficiente. O mesmo aconteceu com o nível de alfabetização do Teste 1 para o Teste 2, apesar de a descrição de suas habilidades pela matriz de referência da Provinha Brasil ser incompatível com as apresentadas nas coletas de Narrativas orais e escritas 2.

Os estudantes 4 e 17, por exemplo, apesar de demonstrarem compatibilidade nas suas competências narrativas, nas coletas realizadas, estas divergiram das habilidades descritas para os níveis de alfabetização 2 e 3, obtidos nos testes da Provinha Brasil 2011.

O estudante 30 apresentou uma incompatibilidade entre a competência narrativa e seu desempenho no Teste 1 da Provinha Brasil no início do ano letivo, pois apresentou uma competência narrativa imatura, o que equivaleria ao nível 1 de alfabetização, mas obteve nível 4 no Teste 1 da Provinha Brasil. No entanto, ao término do ano letivo, mostrou uma melhora na sua competência narrativa, conciliando a sua competência 
proficiente em narrar com o nível 4 obtido no Teste 2 da Provinha Brasil 2011. Tal compatibilidade se apresentou também com o estudante 14, que evidenciou habilidades convergentes em todas as coletas e testes da Provinha Brasil realizados durante todo o ano letivo.

O estudante 8 apresentou uma competência narrativa predominantemente proficiente, uma vez que elaborou uma história composta pelas características contidas na matriz de competência narrativa no nível proficiente em todos os elementos estruturais, exceto na avaliação, ainda que demonstre não dominar o código escrito.

Uma análise longitudinal, do início ao término do ano letivo de 2011, demonstrou, de modo geral, uma manutenção de $42 \%$ dos alunos no nível 3 de alfabetização nos dois testes da Provinha Brasil, evolução de 17\% do nível 2 para o 3 e 25\% do nível 3 para o 4 e baixa de apenas 8\% do nível 5 para o nível 4 e $8 \%$ do 4 para o 3. Apesar das alterações realizadas no barema do Teste 1 para o Teste 2, observamos, a partir do número de acertos desses estudantes nos dois testes, que esse fator não interferiu na manutenção ou alteração em seu nível de alfabetização, exceto a aluna 30, que acertou 19 questões no Teste 2 e, caso fosse aplicado o barema do Teste 1, ela seria classificada no nível 5 de alfabetização.

As produções de narrativas escritas avançaram: de 92\% que produziram, na primeira coleta, narrativas imaturas, sem descrição de cenário ou personagens, com transições incoerentes entre os eventos, sem atentar para o desfecho ou para a finalização dos fatos narrados, 55\% passaram a produzir narrativas emergentes com esses elementos mais ou menos formulados; $27 \%$ produziram narrativas proficientes; e apenas $18 \%$ manteve produção de narrativas predominantemente imaturas. Destaca-se o exemplo do aluno 14, que manteve a média proficiente em todas as coletas. Contudo, apesar de termos identificado nas narrativas os seus elementos macroestruturais, não identificamos o domínio das habilidades contempladas pelos níveis 3 e 4 de alfabetização, conforme proposto na matriz de referências da Provinha Brasil.

Esses resultados mostram que nem sempre o aluno que apresenta um bom desempenho na Provinha Brasil é igualmente proficiente em narrativas. A matriz de competência narrativa consiste em referências que favorecem o reconhecimento dos avanços ou retrocessos, o que é muito útil para um acompanhamento individual dos alfabetizandos nesse processo. A partir desse instrumento auxiliar, pudemos perceber que a manutenção ou o avanço no nível de desempenho em alfabetização auferida pela Provinha Brasil é resultado de fatores diversos, que vão desde o desenvolvimento natural dos alunos de um ano letivo para outro, atividades que ampliam as competências de leitura, até condicionamentos, como a utilização de um livro didático que direcione o treinamento na resposta a determinados tipos de questões. Ao elaborarmos a matriz de competência narrativa, buscamos enfocar habilidades que contemplassem as macroposições propostas por Labov e Waletzky (1967) e as categorias propostas na Narrative Scoring Scheme de Heilmann et al. (2010), 
necessárias para a constituição de uma narrativa. Uma vez elaborada, tal matriz converge com algumas habilidades descritas na matriz de referência da Provinha Brasil, como: localizar informação explícita em textos; reconhecer assunto de um texto e inferir informação, afinal, ao receberem as histórias em quadrinhos não verbais, os alunos precisam identificar a mensagem transmitida através das figuras que formam o conjunto comunicativo para, a partir daí, desenvolverem suas narrativas com início meio e fim. Essa característica conduz à convergência com outra habilidade, a de estabelecer uma relação coerente entre as partes do texto, que se refere à sequência lógica de eventos no desenvolvimento de uma história narrada. Além disso, dentre as habilidades apresentadas no nível 4 do Teste 2 da Provinha Brasil 2011, destaca-se a de identificar elementos que compõem a narrativa, como tempo, espaço e personagem, o que reflete parte da matriz de competência narrativa proposta.

Ao analisar até que ponto os resultados da Provinha Brasil convergem com os da matriz de competência narrativa, esta proposta configura-se em um instrumento complementar à Provinha Brasil no processo de avaliação diagnóstica da alfabetização e letramento.

\section{O tratamento da variação linguística na Provinha Brasil}

Com qual idade a criança dá mostras do amadurecimento da competência sociolinguística e, por conseguinte, faculta a inclusão desse domínio nos programas de ensino de língua materna? É com esse questionamento que investigamos o tratamento da variação linguística como habilidade a ser avaliada na Provinha Brasil. Diferentemente de outros documentos norteadores, a exemplo dos Parâmetros Curriculares Nacionais (PCN) de Língua Portuguesa (Brasil. MEC, 1997), e de outras avaliações, como a Prova Brasil, nos descritores de competência da Provinha Brasil não há nenhuma menção sobre a aferição de habilidades no reconhecimento e posicionamento ante a variação linguística.

A análise da matriz de competências da Provinha Brasil aponta que a variação linguística não faz parte das habilidades avaliadas por esse instrumento. No primeiro eixo, domínio do sistema de escrita, o descritor D3, que avalia a capacidade de o alfabetizando estabelecer relação entre unidades sonoras e suas representações gráficas, aponta como detalhamento da habilidade e exemplificação apenas contextos cuja correspondência grafofonêmica é unívoca: "letras que possuem correspondência sonora única (ex.: p, b, t, d, f)" ou contextos cuja correspondência grafofonêmica não é unívoca "letras com mais de uma correspondência sonora (ex.: "c" e " $g$ ")", mas não se encontra em situação de variação diatópica no território brasileiro, diferentemente, por exemplo, dos casos de rotacismo e iotismo. E, se as diretrizes da matriz de competência barram a variação, obviamente o instrumento também a barrará. Em Freitag (2012, [no prelo]), demonstramos que as questões da 
Provinha Brasil são construídas de modo a blindar a variação linguística nas respostas dos alfabetizandos. E esta blindagem do tratamento da variação na Provinha Brasil aparentemente vai de encontro ao que preconizam os PCN de Língua Portuguesa, que fazem da variedade e diversidade os esteios do ensino de língua. Seria um caso de dissonância entre as diretrizes e a prática nos documentos e ações oficiais norteadores?

Para discutir a implicação da blindagem, na Provinha Brasil, de questões que avaliam a capacidade da criança de reconhecer e operar com a variação linguística, apresentamos as premissas relativas à manifestação da consciência dessa variação e avaliamos até que ponto a competência sociolinguística influencia no aprendizado inicial da leitura.

Seguindo a perspectiva de Hymes (1972), entendemos competência sociolinguística como a habilidade dos indivíduos para usar a linguagem diariamente. Refere-se ao (re)conhecimento de diferenças estilísticas, usualmente chamadas de variação de registro. Não há concordância quanto à faixa etária em que a criança aprende a fazer os ajustes estilísticos aos vários contextos de língua em uso. A criança, por estar inserida em um contexto social constituído por redes de relações (familiares, comunitárias, paritárias, etc.), está exposta à diversidade linguística e vai constituindo sua variedade com base naquelas às quais está exposta. A infância é a primeira faixa etária inerentemente variável, pois as crianças tomam por base a fala de indivíduos mais velhos do seu círculo familiar como modelo. Estudos sociolinguísticos cotejando a fala de adultos e crianças apontam os mesmos condicionamentos, o que, segundo Eckert (1997), sugere que certos padrões da língua não podem ser aprendidos depois de certa idade, o que também é uma evidência de que o desenvolvimento da competência (socio)linguística dá-se cedo. Entretanto, estudos sobre variação linguística na infância são ainda escassos, o que não garante uma margem de segurança para generalizações.

Embora haja muitas proposições sobre a importância do tratamento da variação linguística e resultados para o fundamental maior (BortoniRicardo, 2006), há ainda no Brasil uma carência muito grande de trabalhos que evidenciem a relação entre a variação e a aprendizagem inicial da leitura, foco de avaliação da Provinha Brasil. Dentre os poucos estudos, vale destacar o trabalho de Barrera e Maluf (2004), em que são apresentados resultados de uma investigação que avaliou a influência da variação linguística no aprendizado da escrita com crianças em fase escolar na mesma faixa etária e nível das crianças que são abarcadas pela Provinha Brasil atualmente. Do mesmo modo que a Provinha Brasil, a coleta de dados foi realizada em duas etapas, uma no início do ano e outra ao final. Os resultados obtidos pelas autoras mostram que

as crianças com maior utilização de variação linguística, isto é, aquelas com linguagem mais afastada da norma-padrão, tenderam a apresentar desempenho inferior nas tarefas de leitura, no final do ano letivo, quando comparadas às crianças que mostraram utilizar formas de linguagem mais próximas da norma-padrão. (Barrera; Maluf, 2004, p. 42). 
Essa constatação subsidia a sugestão das autoras de que

um elevado grau de variação linguística no início do ano letivo pode exercer influência negativa sobre o processo de alfabetização, dificultando a aquisição da linguagem escrita, mesmo quando não se observa um padrão claro de estigmatização da linguagem oral dos alunos, como foi o caso da presente pesquisa. Esses resultados podem ser explicados se levarmos em consideração que a utilização de variantes dialetais supõe a necessidade de domínio/memorização de um número maior de irregularidades na correspondência entre letras e sons, bem como de um trabalho pedagógico adequado e lingüisticamente fundamentado por parte das professoras alfabetizadoras. (Barrera; Maluf, 2004, p. 45).

Do ponto de vista sociolinguístico, porém, barrar a variação é antinatural; em um dado momento, o alfabetizando vai se deparar com o fato de que o que ele está aprendendo como conteúdo curricular diverge do seu uso, numa situação artificializante. Defendemos, com base nos pressupostos da Sociolinguística (cf. Freitag, 2011), que a alfabetização não pode ser isolada; o trabalho deve focar a consciência fonológica a partir do contato entre a variedade linguística que o aprendiz traz de casa e a variedade ensinada na escola. Afinal, não é possível ignorar a variação em sala de aula: ainda que ela não esteja presente como conteúdo programático, passível de avaliação, como no caso da Provinha Brasil, vai estar presente em ações. Ao mesmo tempo que sugerem a restrição de contextos de variação, Barrera e Maluf (2004, p. 43), em seu estudo, apresentam dois episódios em que explicitamente a variação era tratada em sala de aula:

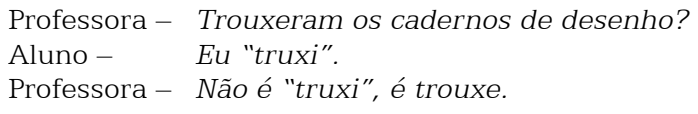

Ou ainda, professora, respondendo ao comentário de um aluno:

Professora - Prá começo de conversa, não é "ingual" que a gente fala. A gente fala igual.

$[\ldots]$

Professora - Não é "sorti" com i, é sorte com e. Quando a gente conversa correndo, a gente fala "sorti", mas escreve sorte.

Aluna - $\quad$ Mas tem umas pessoa que fala errado...

Professora - Tem um monte de gente que fala errado. A professora mesmo fala errado. Quando a gente tá conversando, a gente não se preocupa muito se está falando certo ou errado. Mas pra escrever tem que prestar atenção. Tem palavras que a gente escreve como a gente fala, mas tem outras que enganam a gente.

Apesar da necessidade do trabalho sociolinguístico com o alfabetizando, poucas orientações são dadas para a atividade docente; apenas a título de exemplo, na obra A criança de 6 anos, a linguagem escrita e o ensino fundamental de nove anos: orientações para o trabalho 
com a linguagem escrita em turmas de crianças de seis anos de idade (Maciel; Baptista; Monteiro, 2009) não há menção ao trabalho com a variação linguística. O sucesso ou fracasso do aluno na Provinha Brasil (e podemos estender a todo o processo de alfabetização) tem relação direta com a variedade linguística do professor aplicador (já que se trata de um instrumento também com comandos orais) e a sua relação com a variedade linguística do alfabetizando, pois o não reconhecimento e o despreparo do professor para lidar com a variação influi no fracasso escolar. Os PCN de Língua Portuguesa preconizam as práticas sociais, ou seja, as situações reais de interação como condição para que se dê o ensino de língua; uma concepção de língua heterogênea; um trabalho pedagógico que contemple usos linguísticos e reflexão sobre a língua; o uso da língua adequado aos propósitos comunicativos e demandas sociais; e o combate ao preconceito linguístico. Porém, constatamos que as contribuições de ordem teórico-práticas advindas da Sociolinguística, que repercutem na formação dos professores de língua materna, focando especialmente os professores das séries iniciais, estão em dissonância com a prática, na medida em que o tratamento da variação linguística está ausente no instrumento de diagnóstico da competência em leitura, a Provinha Brasil. Até que ponto é produtivo minimizar efeitos da variedade linguística se a Provinha não é instrumento de ranqueamento, uma vez que não compõe o Ideb? Responder a tais questões se faz necessário para o aprimoramento da Provinha Brasil e para seu objetivo fundamental: auxiliar os gestores e professores a intervir de forma mais eficaz no processo de alfabetização, aumentando as chances de que todas as crianças até os 8 anos de idade saibam ler e escrever, conforme uma das metas previstas pelo Plano de Metas Compromisso Todos pela Educação (Brasil. Decreto..., 2007).

\section{A formação do professor alfabetizador e seu preparo para a aplicação e interpretação dos resultados da Provinha Brasil ${ }^{4}$}

Seguindo as habilidades da Provinha Brasil apresentadas nos descritores de competências, quatro conceitos fazem-se necessários e fundantes à prática pedagógica do professor alfabetizador: alfabetização, consciência fonológica, letramento e gêneros textuais. Logo, para o instrumento de diagnóstico ser produtivo às suas finalidades preconizadas, o professor alfabetizador e/ou o aplicador da Provinha Brasil precisa ter uma formação profissional centrada nas concepções linguísticas que norteiam a elaboração do instrumento.

Para averiguar a aderência entre o professor alfabetizador e os conteúdos e habilidades avaliados na Provinha Brasil, pesquisamos o perfil dos cursos de Pedagogia - que formam professores para atuar nas séries iniciais - no âmbito do projeto Ler + Sergipe: Leitura e letramento para a cidadania. Para tanto, fizemos uma pesquisa nas ementas e programas de disciplinas de cursos de Pedagogia ofertados por instituições de ensino superior no Estado de Sergipe. As entrevistas realizadas com os docentes

\footnotetext{
4 A análise detalhada da formação dos docentes encontrase na dissertação Avaliação de políticas públicas para a alfabetização: formação do professor alfabetizador, concepção e aplicação da Provinha Brasil (Rosário, 2012), em que se apresentam resultados do acompanhamento da aplicação da Provinha Brasil, depoimentos dos docentes com a análise do posicionamento linguístico do alfabetizador, bem como a condução da aplicação da prova em consonância com as orientações do Caderno do Professor/Aplicador.
} 
que aplicaram a Provinha Brasil em 2011 apontam que todos são oriundos de uma das sete instituições que oferecem tal formação no Estado; por isso, acreditamos ser necessário saber quais pressupostos linguísticos alicerçam os cursos de Pedagogia em Sergipe.

A Resolução $n^{\circ} 01$ do Conselho Nacional de Educação (CNE), de 15 de maio de 2006, determina que o curso de Pedagogia tenha carga horária mínima de 3200 horas, das quais 2800 destinam-se à realização de atividades formativas de assistência às aulas, realização de seminários, participação em grupos de estudos etc. Dentro dessa carga horária, o curso deve apresentar disciplinas cujos saberes componham conhecimentos relativos à formação profissional específica (Brasil. CNE, 2006, p. 4) que contemplam disciplinas voltadas para o ensino de língua materna.

Os cursos de Pedagogia em Sergipe são, atualmente, ofertados em duas universidades e cinco faculdades. Algumas instituições solicitaram a não divulgação de seus nomes, motivo pelo qual foram substituídos por um código os nomes de todas as instituições de ensino: numeração de 1 a 7, precedidos da sigla IES (Instituição de Ensino Superior). Dessas instituições, somente uma é pública, da rede federal, seguindo tendência geral para cursos de Pedagogia no País:

[...] os dados indicam que a maioria deles (56\%) era oferecida por instituições de educação superior privadas (32\% delas particulares e $24 \%$ comunitárias ou confessionais ou filantrópicas); $32 \%$ eram oferecidos em instituições estaduais, e apenas 10\% dos cursos de Pedagogia eram oferecidos pelas instituições federais e $2 \%$, por instituições municipais [Tabela 1]. A predominância das instituições privadas na formação de pedagogos fica ainda mais evidente ao se verificar que $62 \%$ dos alunos matriculados estão nessas instituições. (Gatti; Nunes, 2009, p. 11).

O curso de Pedagogia da IES 1 é o mais antigo dos sete pesquisados, pois sua criação data de 1968. Depois, outras instituições se seguiram: IES 2 (1976), IES 3 (1994), IES 4 (2001), IES 5 (2004), IES 6 e IES 7 (2006). Feita a pesquisa na grade curricular do curso de Pedagogia da IES 1, bem como na grade das outras sete instituições que ofertam o curso, identificamos as matérias para a formação profissional específica de ensino de língua materna, sistematizadas no Quadro 4.

Levando-se em consideração os componentes linguísticos necessários ao professor alfabetizador - alfabetização, letramento, consciência fonológica, gêneros textuais e competências (sócio)linguísticas -, a observação da matriz das disciplinas do curso de Pedagogia inerentes ao estudo de língua materna aponta que, no que diz respeito aos dois primeiros pressupostos subjacentes à Provinha Brasil, alfabetização e letramento, todas as instituições de ensino superior analisadas (embora com nomenclaturas ou enfoques diferenciados) trazem em sua grade curricular esses componentes. A IES 1 e a IES 4 compartilham o mesmo nome, Alfabetização. A primeira aborda os conteúdos em três períodos e a subclassifica em Alfabetização I, Alfabetização II e Alfabetização III, a segunda, em dois, atribuindo-lhes os mesmos nomes, respectivamente. 


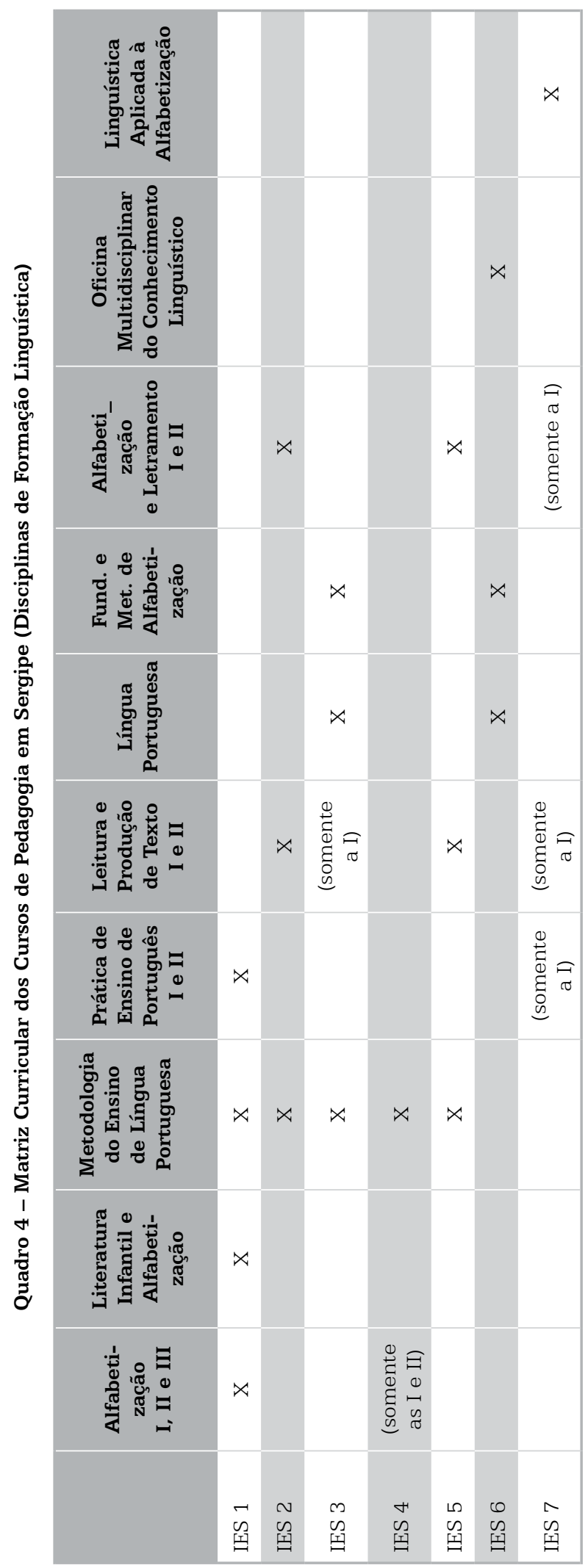


A IES 5 e a IES 2 nomeiam a disciplina como Alfabetização e Letramento. A primeira trabalha os conteúdos em um momento e a segunda, em dois, Alfabetização e Letramento I e Alfabetização e Letramento II. A IES 6 e a IES 3 nomenclam as teorias como Fundamentos e Metodologia da Alfabetização. Somente a IES 7 atrela a alfabetização à linguística e envolve as referidas teorias nomeando a disciplina como Linguística Aplicada à Alfabetização.

Embora essas instituições tragam em seus cursos os nomes das concepções coerentes com as trabalhadas na Provinha Brasil, as ementas e programas de curso apontam uma direção conceitual que não condiz com o que é preconizado na avaliação, especificamente nos descritores de competências e sub-habilidades. As teorias apresentadas nas ementas das IES 1 e 4 sustentam-se na metodologia da alfabetização de Paulo Freire, embora o próprio educador preferisse dizer que não tinha método, mas uma compreensão que ele chamava de "crítica dialética da prática educativa, dentro da qual, necessariamente, há uma certa metodologia, um método" (apud Oliveira, 2004, p. 83). As IES 2, 3, 5 e 6 focam nas teorias ditas "construtivistas", que, de acordo com Oliveira (2004), não deveriam ser chamadas teorias, visto que em exame às literaturas nacional e internacional há resultados satisfatórios que ajudam a definir o construtivismo.

Tais constatações, à luz da neurociência da leitura (Moraes, 1996, Deheane, 2012, Scliar-Cabral, 2003, Oliveira, 2004), sugerem que as instituições trabalham, conforme evidenciado em suas ementas e programas, com concepções de alfabetização que não preparam os professores para alfabetizar, já que ignoram o início do processo de aprendizagem em leitura, dado através da assimilação do princípio alfabético, e são dissonantes daquilo que a Provinha Brasil avalia em seus descritores de competências e habilidades. Por exemplo, com exceção da IES 4, nenhuma das outras instituições de nível superior traz a disciplina Fonética/Fonologia em seu ementário. Ainda assim, esses conteúdos não aparecem sob a forma de disciplina, mas diluídos em uma disciplina denominada Comunicação e Expressão, de 80 horas, que deve abordar, além dos princípios da fonética, a morfologia, a sintaxe e a relação entre linguagem oral e escrita - o que significa que menos de 20 horas-aula em todo o curso de formação serão dedicados a um dos esteios do processo de alfabetização: o trabalho com a consciência fonológica.

A única instituição pesquisada que apresenta uma proposta voltada para as abordagens de alfabetização e letramento aderente à proposta da Provinha Brasil é a IES 7, que inova, inclusive, na nomenclatura da disciplina: Linguística Aplicada à Alfabetização. Em sua ementa, chamam a atenção o estudo do funcionamento e da estrutura de uma língua, a proposta de uma comparação entre a competência linguística e o processo de alfabetização, além da apresentação das contribuições da Sociolinguística, Fonologia e Psicolinguística para o processo de alfabetização. A bibliografia é coerente com a ementa e o conteúdo letramento não é mencionado na ementa da disciplina desta IES, mas é apresentado na bibliografia. 
Somente as IES 2, 3 e 5 trazem na graduação em Pedagogia a disciplina de Produção de Textos. Dessas, a IES 3 é a única que, em sua ementa e programa, refere-se às concepções de gêneros textuais; apesar da referência a esse pressuposto, ele é somente um dos conteúdos propostos na ementa. Além disso, não apresenta em sua bibliografia nenhum autor que trate dos gêneros textuais, mas deixa bem clara a sua adesão aos tipos textuais que, ao contrário dos gêneros, "constituem sequências linguísticas ou de enunciados e não são textos empíricos" (Marchuschi, 2008, p. 23).

O estudo de gêneros textuais, terceira concepção apresentada, é importante, pois atende às necessidades do segundo eixo da matriz (leitura), o qual requer o estudo da compreensão, que, por sua vez, pressupõe estratégias, uma das quais consiste no domínio sobre as características de diversos tipos de gêneros. A compreensão de um texto será facilitada se já se souber de que gênero se trata, quem são os emissores, personagens, contexto no qual foi escrito, enfim, as inúmeras características que retratam o tipo de gênero.

É no processo inicial de alfabetização, quando a criança convive com vários gêneros de texto, que se aprendem os procedimentos necessários para a prática de estratégias mais amplas e abrangentes da leitura, já que cabe à alfabetização o ensino do código e do sistema notacional. Em contato com o texto, nessa perspectiva dos gêneros e do desenvolvimento da consciência sociocomunicativa, o aluno infere do texto a sua função social, o seu objetivo e vai compreendendo que, por esses motivos, variadas são as formas de se ler. A escola é que deve formar o aluno leitor, gerando oportunidade de ele vivenciar, no processo de alfabetização, a "funcionalidade de cada gênero e da própria linguagem escrita" (Brasil. Decreto..., 2007, p. 25).

O conceito de consciência fonológica foi mencionado na ementa da IES 5, contudo, nenhuma bibliografia que o contemplasse foi apresentada no programa de disciplina.

Para finalizar a averiguação dos programas e ementas, restam os pressupostos sociolinguísticos, cujo conhecimento de suas teorias, como vimos, incidirá diretamente sobre a postura do professor, que tratará a variedade linguística como natural do falar humano e que, portanto, não pode ser vista como erro. Tais teorias são nominadas de "variedades linguísticas", na ementa de Metodologia do Ensino de Língua Portuguesa da IES 4, e de "Sociolinguística", na ementa de Linguística Aplicada à Alfabetização, da IES 7, e na de Metodologia de Alfabetização, da IES 2. Apesar disso, o exame dos programas de curso aponta que não há bibliografias que possam dar conta dessas concepções. A IES 3, embora em meio à profusão de conteúdos metalinguísticos com os quais planeja trabalhar, faz alusão ao estudo da língua falada e dos níveis de linguagem, na ementa da disciplina intitulada Língua Portuguesa.

A ausência de formação linguística impele o professor alfabetizador a trabalhar com uma metodologia de ensino de língua centrada em uma dicotomia excludente e discriminatória que, junto aos alunos que estão 
iniciando seus estudos oficiais em língua materna, pode ter resultados negativos e irreversíveis, afinal

a Sociolinguística alerta a escola sobre a necessidade de abordagem da heterogeneidade linguística, sobre as diferenças, especialmente, porque a democratização trouxe à escola alunos de vivências diversas. A Sociolinguística contribui para a nova postura do professor, para a definição de conteúdos e metodologias. (Coan; Freitag, 2010, p.178).

Das instituições apresentadas, a responsável pela formação das docentes que aplicaram a Provinha Brasil na coleta realizada foi a IES 1. Constatamos que essa instituição de ensino é deficitária no que tange à exposição das bases linguísticas subjacentes à elaboração da Provinha Brasil. O letramento é apresentado a partir da proposta metodológica de Paulo Freire, que extrai, da realidade do alfabetizando, uma palavra geradora para ensinar o processo de decodificação. Trata-se de processo essencial à alfabetização, mas falho no que diz respeito à contemplação da consciência fonêmica, pois somente se limita à sílaba, excluindo os fonemas. Além disso, o texto é deixado de lado, na medida em que, ao partir da realidade, prioriza-se o contexto. Dessa maneira, os gêneros textuais como práticas sociais também não são trabalhados. A Sociolinguística, as variedades e a linguagem oral ou o preconceito linguístico não fazem parte dos programas de curso do componente ensino de língua materna. Essa realidade linguística deficiente resulta numa formação que traz prejuízos na condução do processo de aprendizagem da leitura e escrita.

Com a análise dos programas dos cursos de formação de professores alfabetizadores, constatamos que existe um descompasso entre o que é ensinado nos cursos de Pedagogia do Estado de Sergipe e o que é cobrado do aluno na Provinha Brasil. Faz-se necessário esclarecer que não devemos chegar a uma conclusão precipitada e superficial de que os cursos de Pedagogia deveriam oferecer em sua grade conteúdos que contemplem as concepções da Provinha Brasil. Porém, acreditamos que a ausência dessas concepções na formação do professor alfabetizador, que é quem aplica a Provinha Brasil e faz uso de seus resultados na sua prática pedagógica, seja um empecilho para que os alunos aprendam a ler proficientemente e na idade adequada.

\section{Considerações finais}

As políticas públicas de avaliação da educação mobilizam um montante de recursos considerável; a sua eficiência e otimização é uma questão, antes de ser educacional, econômica. A oportunidade de uma avaliação externa e imparcial, isenta de comprometimento, possibilita trazer resultados que podem vir a balizar as ações. São essas as contribuições mais amplas que esperamos com os resultados até agora alcançados com o desenvolvimentos do projeto Ler+Sergipe: Leitura para o letramento e cidadania. Com a análise em torno da Provinha Brasil, constatamos que: 
- Há uma divergência entre a competência narrativa do alfabetizando e o seu nível de alfabetização no instrumento de diagnóstico, com a necessidade de revisão dos descritores de competências e habilidades, a fim de captar as nuanças da competência narrativa. Apresentamos um instrumento complementar de diagnóstico da competência narrativa que pode auxiliar o professor alfabetizador em sua prática pedagógica;

- A variação linguística presente na vida do indivíduo a partir do momento que ele nasce e se integra a uma dinâmica de agrupamento social está ausente dos descritores de competências e habilidades do instrumento de diagnóstico da alfabetização. Notamos a ausência de estudos mais específicos nesta área, mas as bases sociolinguísticas que norteiam os documentos oficiais, tais como os PCN de Língua Portuguesa (Brasil, 1997), reforçam a necessidade de inclusão do tratamento da variação.

- A análise dos programas dos cursos de formação de professores alfabetizadores aponta descompasso entre o que é ensinado nos cursos de Pedagogia do Estado de Sergipe e o que é cobrado do aluno na Provinha Brasil, sugerindo a ausência e a necessidade de diálogo entre academia e postulantes de políticas educacionais.

Estes apontamentos devem ser considerados por gestores, na medida em que podem auxiliá-los na tomada de decisões e elaboração de planejamentos, bem como subsidiar as propostas de atividades que auxiliem no desenvolvimento de habilidades de leitura e escrita.

\section{Referências bibliográficas}

ALMEIDA, Ayane Nazarela Santos. A competência narrativa na Provinha Brasil: um estudo do desempenho dos estudantes da EMEF Tenisson Ribeiro, Aracaju/SE. 2012. 127 f. Dissertação (Mestrado em Letras) - Universidade Federal de Sergipe, São Cristóvão, 2012.

BAMBERG, Michael. Why young American English-speaking children confuse anger and sadness: a study of Grammar in practice. In:

NELSON, Keith E.; AKSU-KOÇ, Ayhan; JOHNSON, Carolyn E. Children's language: developing narrative and discourse competence. New Jersey: LEA, 2001. v. 10, p. 55-72.

BARRERA, Sylvia Domingos; MALUF, Maria Regina. Variação linguística e alfabetização: um estudo com crianças da primeira série do ensino fundamental. Psicologia Escolar e Educacional, Campinas, v. 8, n. 1, p. 35-46, 2004. 
BARTHES, Roland. Introdução à análise estrutural das narrativas. In: . A aventura semiológica. São Paulo: Martins Fontes, 2001. p. 103-152.

BERMAN, Ruth A. Setting the narrative scene: how children begin to tell a story. In: NELSON, Keith E.; AKSU-KOÇ, Ayhan; JOHNSON, Carolyn E. Children's language: developing narrative and discourse competence. New Jersey: LEA, 2001. v. 10, p. 1-30.

BORTONI-RICARDO, Stella Maris. Métodos de alfabetização e consciência fonológica: o tratamento de regras de variação e mudança. Scripta, Belo Horizonte, v. 9, n. 18, p. 201-220, 2006.

BRASIL. Conselho Nacional de Educação (CNE). Conselho Pleno. Resolução no 01, de 15 de maio de 2006. Institui diretrizes curriculares nacionais para o curso de graduação em Pedagogia, licenciatura. Disponível em: < http://portal.mec.gov.br/cne/arquivos/pdf/rcp01_06. pdf>. Acesso em: 18 abr. 2013.

BRASIL. Decreto n 6.094, de 24 de abril de 2007. Dispõe sobre a implementação do Plano de Metas Compromisso Todos pela Educação, pela União Federal, em regime de colaboração com Municípios, Distrito Federal e Estados, e a participação das famílias e da comunidade, mediante programas e ações de assistência técnica e financeira, visando a mobilização social pela melhoria da qualidade da educação básica. Diário Oficial da União, Brasília, DF, 25 abr. 2007. Seção 1, p. 5. Disponível em: <http://www.in.gov.br/visualiza/index.jsp?jornal=1\&pa gina $=5 \&$ data $=25 / 04 / 2007>$. Acesso em: 17 abr. 2013 .

BRASIL. Instituto Nacional de Estudos e Pesquisas Educacionais Anísio Teixeira (Inep). Provinha Brasil: guia de aplicação, Teste 1. Brasília, 2011a.

BRASIL. Instituto Nacional de Estudos e Pesquisas Educacionais Anísio Teixeira (Inep). Provinha Brasil: guia de correção e interpretação de resultados, Teste 1. Brasília, 2011b.

BRASIL. Instituto Nacional de Estudos e Pesquisas Educacionais Anísio Teixeira (Inep). Provinha Brasil: reflexões sobre a prática, Teste 1. Brasília, 2011c.

BRASIL. Instituto Nacional de Estudos e Pesquisas Educacionais Anísio Teixeira (Inep). Provinha Brasil: guia de aplicação, Teste 2. Brasília, 2011d.

BRASIL. Instituto Nacional de Estudos e Pesquisas Educacionais Anísio Teixeira (Inep). Provinha Brasil: guia de correção e interpretação de resultados, Teste 2. Brasília, 2011e. 
BRASIL. Instituto Nacional de Estudos e Pesquisas Educacionais Anísio Teixeira (Inep). Provinha Brasil: reflexões sobre a prática, Teste 2.

Brasília, 2011f.

BRASIL. Lei de Diretrizes e Bases da Educação. Disponível em: < http:// www.planalto.gov.br/ccivil_03/Leis/L9394.htm>. Acesso em: 10 set.

2011.

BRASIL. Ministério da Educação (MEC). Parâmetros Curriculares Nacionais $1^{a}$ a $4^{a}$ séries. 1997. Disponível em: <http://portal.mec.gov. br/seb/arquivos/pdf/blegais >. Acesso em: 10 set. 2011.

COAN, M.; FREITAG, R. M. K. Sociolinguística variacionista: pressupostos teórico-metodológicos e propostas de ensino. DomíniosdeLingu@gem, Uberlândia,v. 4, n. 2, p.173-194, 2. sem. 2010. Disponível em: <http://www.seer.ufu.br/index.php/ dominiosdelinguagem/article/view/11618/6863>. Acesso em: 8 abr. 2012 .

CRISTOFOLINI, Carla. Algumas considerações a respeito do letramento na Provinha Brasil. Working Papers em Linguística, Florianópolis, v. 11, n. 2, p. 25-35, 2010.

CRISTOFOLINI, Carla. Refletindo sobre a Provinha Brasil a partir das dimensões sociocultural, linguística e cognitiva da leitura. Alfa: Revista de Linguística, São Paulo, v. 56, n. 1, p. 217-247, 2012.

DEHEANE, Stanislas. Os neurônios da leitura. Porto Alegre: Penso, 2012.

ECKERT, Penelope. Ages as a sociolinguistic variable. In: COULMAS, F. (Ed.). The handbook of sociolinguistics. Oxford: Blackwell, 1997. p. 151-167. Disponível em: <http://www.blackwellreference.com/ subscriber/tocnode?id=g9780631211938_chunk_g97806312119381>.

ESTEBAN, Maria Teresa. Provinha Brasil: desempenho escolar e discursos normativos sobre a infância. Sísifo: Revista de Ciências da Educação, Lisboa, n. 9, p. 47-56, maio/ago. 2009.

FREITAG, Raquel Meister Ko. Entre norma e uso, fala e escrita: contribuições da sociolinguística à alfabetização. Nucleus, Ituverava, v. 8, n. 1, abr. 2011.

FREITAG, Raquel Meister Ko. Sociolinguística na alfabetização: entre a teoria e a prática. Olhar de professor, Ponta Grossa. [No prelo].

GATTI, Bernardete A.; NUNES, Marina M. R. Formação de professores para o ensino fundamental: estudo de currículos das licenciaturas em 
Pedagogia, Língua Portuguesa, Matemática e Ciências Biológicas. São Paulo: Fundação Carlos Chagas, 2009.

HEILMANN, J. et al. Properties of the narrative scoring scheme using narrative retells in young school-age children. American Journal of Speech-Language Pathology, v. 19, p. 154-166, May 2010.

HYMES, Dell. On competence communicative. In: PRIDE, J.; HOLMES, J. Sociolinguistics. Harmondsworth: Penguin Books, 1972. p. 267-293.

KADERAVEK, J. N.; SULZBY, E. Narrative production by children with and without specific language impairment oral narratives and emergent readings. Journal of Speech Language and Hearing Research, v. 43, n. 1, p. 34-49, Feb. 2000.

LABOV, William; WALETZKY, Joshua. Narrative analysis: oral versions of personal experience. In: HELM, J. (Org.). Essays on the verbal and visual arts. Seattle: University of Washingtons Press, 1967. p. 12-44.

MACIEL, Francisca Izabel Pereira; BAPTISTA, Mônica Correia; MONTEIRO, Sara Mourão (Org.). A criança de 6 anos, a linguagem escrita e o ensino fundamental de nove anos: orientações para o trabalho com a linguagem escrita em turmas de crianças de seis anos de idade. Belo Horizonte: UFMG/FaE/Ceale, 2009.

Disponível em: <http://www.fcee.sc.gov.br/index.php?option=com_ docman\&task $=$ cat_view\&gid $=30 \&$ Itemid $=91>$.

MARCUSCHI, Luiz Antônio. Produção textual, análise de gêneros e compreensão. Parábola Editorial: São Paulo, 2008.

MORAES, José. A arte de ler. São Paulo: Unesp, 1996.

MORAIS, Artur Gomes de; LEAL, Telma Ferraz; ALBUQUERQUE, Eliana Borges Correia. Provinha Brasil: monitoramento da aprendizagem e formulação de políticas educacionais. Revista Brasileira de Política e Administração da Educação, Recife, v. 25, n. 2, p. 301-320, maio/ago. 2009.

NELSON, Keith E.; AKSU-KOÇ, Ayhan; JOHNSON, Carolyn E. Children's language: developing narrative and discourse competence. New Jersey: LEA, 2001. v. 10.

OLIVEIRA, João Batista Araújo e. Alfabetização de crianças e adultos: novos parâmetros. Belo Horizonte: Alfa Educativa, 2004.

ROSÁRIO, Mônica Maria Soares. Avaliação de políticas públicas para a alfabetização: formação do professor alfabetizador, concepção e 
aplicação da Provinha Brasil. 2012. Dissertação (Mestrado em Letras) Universidade Federal de Sergipe, São Cristóvão, 2012.

SCLIAR-CABRAL, Leonor. Princípios do sistema alfabético do português do Brasil. São Paulo: Contexto, 2003.

SOUSA, Maurício de. Almanaque do Chico Bento. Rio de Janeiro: Panini Comics, 2011. n. 26.

VENEZIANO, Edy. Interactional processes in the origins of the explaining capacity. In: NELSON, Keith E.; AKSU-KOÇ Ayhan;

JOHNSON, Carolyn E. Children's language: developing narrative and discourse competence. New Jersey: LEA, 2001. v. 10, p. 113-141.

Raquel Meister Ko Freitag, doutora em Linguística pela Universidade Federal de Santa Catarina (UFSC), é professora do Departamento de Letras Vernáculas e do Programa de Pós-Graduação em Letras da Universidade Federal de Sergipe (UFS), Aracaju, Sergipe, Brasil.

rkofreitag@uol.com.br

Ayane Nazarela Santos Almeida é doutoranda em Letras e Linguística na Universidade Federal de Alagoas (UFAL), Maceió, Alagoas, Brasil.

ayanesantos@hotmail.com

Mônica Maria Soares Rosário, mestre em Letras pela Universidade Federal de Sergipe (UFS), é professora da educação básica da Rede Pública Municipal de Aracaju-SE, Aracaju, Sergipe, Brasil.

moniclingua@hotmail.com

Recebido em $1^{\circ}$ de setembro de 2012.

Aprovado em $1^{\circ}$ de março de 2013. 